\title{
Impactos de se ignorarem os efeitos genéticos não-aditivos de dominância na avaliação genética animal
}

\author{
Elizângela Emídio Cunha ${ }^{1}$, Ricardo Frederico Euclydes ${ }^{2}$, Robledo de Almeida Torres ${ }^{2}$, José

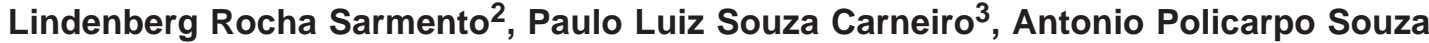 \\ Carneiro $^{4}$
}

\author{
1 Departamento de Genética, CB, UFRN. Natal, RN. \\ 2 Departamento de Zootecnia, CCA, UFV. Viçosa, MG. \\ ${ }^{3}$ Departamento de Ciências Biológicas, CCB, UESB. Jequié, BA. \\ ${ }^{4}$ Departamento de Estatística, CCA, UFV. Viçosa, MG.
}

RESUMO - Objetivou-se com este estudo avaliar os impactos de se ignorarem os efeitos de dominância sobre a estimação de parâmetros genéticos e a predição de valores genéticos pelo método da máxima verossimilhança restrita sob modelo animal aditivo empregando-se o MTDFREML. Para a mesma arquitetura genômica, foram simulados dois modelos de ação gênica: um deles incluiu apenas efeitos aditivos dos genes e o outro, efeitos aditivos e dominância completa e positiva para $100 \%$ dos locos. Sob cada modelo genético, foram geradas três populações-base correspondentes às características com herdabilidades de 0,15 (baixa), 0,30 (média) e 0,60 (alta). A partir das populações-base, foram geradas as populações iniciais, que, submetidas a seleção e a acasalamentos ao acaso, durante seis gerações consecutivas e discretas, resultaram cada uma em 18.000 indivíduos com registro. As estimativas dos componentes de variância e herdabilidade obtidas no modelo com ação gênica aditiva foram semelhantes aos seus valores reais para todas as características, ao passo que, sob ação gênica de dominância, todos os componentes foram superestimados, principalmente a variância genética aditiva. A variância de dominância não-estimada pelo modelo animal adotado foi redistribuída entre os componentes genético aditivo e residual estimados. Houve perda na acurácia da avaliação genética sob o modelo genético com dominância e essa perda foi traduzida por correlações mais baixas entre os valores genéticos verdadeiros e preditos dos animais. Há necessidade de novos estudos, já que os genomas simulados podem não corresponder aos sistemas biológicos verdadeiros.

Palavras-chave: BLUP, componentes de variância, herdabilidade, interação intraloco, modelo animal, simulação

\section{Impacts of ignoring the non-additive genetic effects of dominance on animal genetic evaluation}

\begin{abstract}
The objective of this study was to evaluate impacts of ignoring the dominance effects on the estimation of genetic parameters and prediction of genetic values by the restricted maximum likelihood method, under the additive animal model, using MTDFREML. Two gene action models were simulated for the same genomic architecture: one model that included only additive effects of the genes and the other with additive effects and positive and complete dominance into $100 \%$ of the loci. Under each genetic model, three base populations were generated corresponding to the characteristics with heritabilities of 0.15 (low), 0.30 (average) and 0.60 (high). Starting from the base populations the initial populations were generated which by selection and mating at random, for six consecutive and discrete generations, each one produced 18,000 animals with record. The estimates of the components of variance and heritability obtained in the model with additive gene action were similar to the actual values for all traits, while under dominance gene action, every component was overestimated, especially the additive genetic variance. The non-estimated dominance variance by the animal model adopted was redistributed between the additive genetic and residual components estimated. Accuracy was lost in the genetic evaluation, under the genetic model with dominance, that resulted in smaller correlations between the actual and predicted breeding values of the animals. Additional studies are needed since the simulated genome might not correspond to the true biological systems.
\end{abstract}

Key Words: animal model, BLUP, components of variance, heritability, intralocus interaction, simulation 


\section{Introdução}

Comumente, na maioria das avaliações genéticas em melhoramento animal, pressupõe-se que os genes que determinam o fenótipo de uma característica agem unicamente pela adição de seus efeitos, pois apenas os alelos podem ser transmitidos dos pais aos filhos. Essa hipótese tem a finalidade principal de simplificar os modelos de avaliação, tornando-os estatisticamente mais tratáveis, haja vista a enorme complexidade funcional dos sistemas gênicos.

O interesse crescente pelos efeitos da dominância apoia-se na intensa utilização do sêmen de poucos reprodutores de superioridade genética comprovada e no uso de biotecnologias reprodutivas modernas (ovulação múltipla, fertilização in vitro, transferência de embriões e clonagem). Em razão disso, verifica-se aumento do número de progênies de irmãos completos, o que aumenta o parentesco na população dentro e entre gerações e os relacionamentos genéticos de dominância (VanRaden et al., 1992).

Inúmeros esforços têm sido feitos, com base na literatura, para inclusão da dominância como efeito aleatório genético não-aditivo nos modelos mistos de avaliação genética sob modelo animal com uso do BLUP (melhor preditor linear não-viesado). Isso poderia aumentar a acurácia das avaliações (Misztal, 1997), todavia há algumas dificuldades inerentes ao cômputo da matriz de dominância e de sua inversa (Schaeffer, 2003).

Varona et al. (1998) afirmam que a inclusão desse efeito na avaliação genética resulta em dois tipos de mudanças: a primeira é que se torna possível determinar combinações específicas de acasalamentos, o que possibilitaria selecionar o melhor parceiro para um determinado animal, desde que se conheça o valor da variância de dominância; já a segunda é que as soluções de outros efeitos, incluindo os valores genéticos aditivos, poderiam se alterar, sobretudo para animais com muitos irmãos completos em seus pedigrees. Autores como Hayes \& Miller (2000) e Ishida \& Mukai (2004) ressaltam que ignorar a variância não-aditiva dentro de raças poderia conduzir a predições viesadas de valores genéticos e, dessa forma, comprometer a ordem de classificação de touros nas comparações internacionais.

Objetivou-se avaliar geneticamente populações simuladas, por meio da metodologia de modelos mistos, a fim de investigar os impactos de se ignorarem os efeitos da dominância no modelo animal sobre a estimação dos componentes de variância e a predição de valores genéticos.

\section{Material e Métodos}

Os dados analisados foram obtidos por meio de simulações em nível de gene, empregando-se o programa computacional GENESYS (Euclydes, 1996), escrito em linguagem Fortran. Esse programa permite obter o valor fenotípico de um indivíduo a partir da simulação dos efeitos gênicos de cada loco, considerando os efeitos aditivos dos alelos, bem como os não-aditivos resultantes de interações intraloco, além dos efeitos de meio. Diferentes estruturas de população podem ser geradas de modo a permitir a avaliação de estratégias de acasalamento, de seleção, de teste de pressuposições, de distribuições matemáticas etc.

Foi simulado um genoma-molde com 600 locos quantitativos bialélicos, distribuídos ao acaso por 29 pares de cromossomos autossômicos de tamanhos aleatórios, com variação entre si na ordem de $10 \%$. O comprimento total do genoma foi de 3.000 cM e não foram simulados cromossomos sexuais.

Considerando o percentual de $100 \%$ dos locos, foram permitidos dois tipos de ação gênica dos alelos: completamente aditiva, com apenas efeitos aditivos dos genes; e completamente heterótica, com efeitos aditivos e de dominância. Deste modo, tendo por base a mesma configuração do genoma, foram estruturados dois modelos de ação gênica, um deles o modelo aditivo e o outro o modelo heterótico. Considerou-se o tipo de dominância completa e direcional no sentido positivo ou do alelo favorável $(\mathrm{d} / \mathrm{a}=+1)$. Assim, o valor genotípico do indivíduo heterozigoto (d) era idêntico ao do homozigoto dominante (a). A relação d/a mede o que se denomina grau de dominância de um gene.

Independentemente do tipo de ação gênica, a frequência inicial do alelo favorável nos locos quantitativos foi simulada com média de 0,50 e, assim como os efeitos aditivos dos genes, seguiu a distribuição normal. Já o desvio da dominância ao longo dos locos seguiu a distribuição uniforme. Interações não-aditivas do tipo epistáticas e efeitos fixos como o de sexo não foram simulados. O efeito aleatório de ambiente temporário foi simulado com distribuição normal.

Os efeitos genéticos foram obtidos considerando-se que o valor genotípico $(G)$ de cada loco era constituído do valor genético aditivo $(A)$ e do desvio da dominância $(D)$ : $G=A+D$. O valor genotípico individual foi obtido aplicando-se o somatório à fórmula anterior em relação a todos os locos controlando a expressão da característica no indivíduo. O valor fenotípico individual foi integralizado pelos componentes de valor genotípico e de efeito ambiental, desconsiderando a interação genótipo-ambiente, da 
seguinte forma: $F=G+E$, em que $F$ é o fenótipo do indivíduo e $E$, o ambiente temporário que o afeta. Nas populações simuladas sem efeitos de dominância, $G$ era o próprio valor aditivo $A$.

A cada geração, as variâncias dos efeitos aditivos (VA) e de dominância $(V D)$ foram simuladas de acordo com:

$V A=\sigma_{A}^{2}=\sum_{i=1}^{n} 2 p_{i} q_{i} \alpha_{i}^{2}$ e $V D=\sigma_{D}^{2}=\sum_{i=1}^{n} 4 p_{i}^{2} q_{i}^{2} d_{i}^{2}$, em que $n$ é o número total de locos; e considerando o loco $i, p_{i}$ e $q_{i}$ são as frequências gênicas, na população, dos alelos favorável e desfavorável, respectivamente; e $\alpha_{i}=a_{i}+d_{i}\left(q_{i}-p_{i}\right)$ é o efeito médio de substituição gênica no loco $i$, de modo que $a_{i}$ é o seu valor genético aditivo e $d_{i}$, o seu desvio da dominância.

Sob cada modelo genético, foram avaliadas, de maneira independente, três características quantitativas influenciadas por todos os genes do genoma, o que caracterizou a existência de seis populações-base distintas.

Para as três características, foram simulados um único valor de variância genética aditiva, igual a 0,90 , de modo a facilitar as comparações; e valores apropriados de variância residual que resultassem nas herdabilidades iniciais 0,15 (baixa), 0,30 (média) e 0,60 (alta), correspondentes às características estudadas, cujas médias e variâncias fenotípicas foram de 12,0 e 6,0; 10,0 e 2,99; e 8,0 e 1,49, respectivamente.

A partir de cada estrutura (modelo genético característica), foi obtida uma população-base constituída de 1.000 indivíduos, com proporção igual entre os sexos e predominantemente heterozigota. Os indivíduos dessa população foram gerados por processos inteiramente aleatórios, que determinaram inclusive seu sexo e caracterizaram a inexistência de parentesco entre eles, uma vez que na gametogênese não houve segregações mendelianas.

Da população-base foram escolhidos ao acaso e assim acasalados 10 machos e 100 fêmeas, que produziram 10 progênies por acasalamento, totalizando 1.000 indivíduos. Essa nova população foi denominada população inicial, pois nela se verificou o início dos laços de parentesco entre os animais.

Pela reprodução da população inicial, nos diferentes genomas, foram obtidas as populações a serem avaliadas. Assim, foi gerado um total de 18.000 animais com informações por arquivo, com uso da estratégia de seleção e acasalamentos ao acaso, durante seis gerações consecutivas e discretas. Em cada geração, as populações apresentaram, em comum, a seguinte estrutura: número de machos e de fêmeas escolhidos para a reprodução de 30 e
300, respectivamente; número de progênies por casal de 10 ; tamanho real de 3.000; tamanho efetivo de 109,09; e número de famílias de irmãos completos de 300 , ou seja, $100 \%$ da população. Para o cálculo do tamanho efetivo da população $\left(N_{e}\right)$, empregou-se a fórmula proposta por Wright (1931), citada por Falconer (1987): $N_{e}=\frac{4 N_{m} N_{f}}{N_{m}+N_{f}}$, em que $N_{m}=$ número de machos e $N_{f}=$ número de fêmeas efetivamente acasalados.

Ao todo, foram avaliadas seis populações que corresponderam à combinação dos modelos genéticos aditivo e heterótico com as três características estudadas. Os arquivos diferentes foram analisados, utilizando-se o programa MTDFREML (Multiple Trait Derivative-Free Restricted Maximum Likelihood), descrito por Boldman et al. (1995), para estimação dos componentes de variância e predição dos valores genéticos dos animais, por meio da metodologia de modelos mistos.

Empregou-se um único modelo para a análise de característica simples, independentemente se o genoma simulado continha apenas efeitos aditivos dos genes ou ambos os efeitos aditivos e de dominância. Nesse sentido, todas as análises foram conduzidas como se existissem apenas os efeitos aditivos dos genes, mesmo quando estavam presentes os efeitos da dominância.

Matricialmente, o modelo animal adotado para o estudo de característica única foi: $y=X b+Z u+e$, em que: $y=$ vetor de observações da característica medida nos indivíduos; $X$ e $Z$ = matrizes de incidência que relacionam as observações aos efeitos fixos e aleatórios, respectivamente; $b$ = vetor dos efeitos fixos, tendo a média como único elemento; $u=$ vetor dos efeitos aleatórios (valores genéticos dos animais); e $e=$ vetor dos erros.

O número de animais constantes da matriz de parentesco foi de 20.000, pois foram incluídos os animais das gerações base e inicial, embora suas informações não tenham sido consideradas nas outras análises.

Os valores iniciais (priors) dos componentes de variâncias aditiva e residual fornecidos ao programa foram obtidos a partir dos dados simulados. Não foram fornecidos os valores iniciais da variância de dominância presente nos arquivos simulados com desvios da dominância, já que o modelo aditivo de avaliação não acomodava esse efeito.

Para avaliar os impactos de se desconsiderarem os efeitos da dominância sobre a avaliação genética dos animais, foram utilizados: a) viés em percentual para os componentes de variância e herdabilidade, calculado como a razão da diferença entre os valores estimado e real 
(ou verdadeiro) pelo valor real; b) correlação de Pearson entre os valores genéticos reais e preditos; c) correlação entre as ordens de classificação dos animais (correlação de Spearman ou de rank) com base nos valores genéticos reais e preditos; d) porcentagem de indivíduos que seriam selecionados em comum pelos valores genéticos reais e preditos, considerando diferentes intensidades de seleção.

As correlações de Pearson e Spearman servem como indicadores da acurácia das avaliações genéticas, pois, na classificação dos animais, informam a correspondência entre os valores genéticos verdadeiros e preditos.

Os parâmetros genéticos dos dados simulados, as correlações de Pearson e Spearman e a porcentagem de animais selecionados em comum foram obtidos utilizando-se o pacote estatístico SAS (1999).

\section{Resultados e Discussão}

Considerando a ação gênica aditiva, os valores estimados dos componentes de variância e da herdabilidade no sentido restrito (Tabela 1 ) diferiram pouco dos respectivos valores reais, independentemente da característica. Nesse modelo, a variância genética aditiva estimada equivale à variância genotípica.

Quando a expressão da característica foi influenciada por efeitos genéticos de dominância (Tabela 2), observou-se aumento no valor real da variância genotípica e no da variância fenotípica, ocasionado pela presença da variância de dominância em relação à situação na qual apenas os efeitos aditivos dos genes determinaram o fenótipo.

No modelo heterótico, os valores estimados para a variância fenotípica foram similares aos reais, notadamente para as características de baixa e alta herdabilidades, enquanto a variância genética aditiva estimada aproximou-se mais da variância genotípica real, nas três herdabilidades. De modo geral, as diferenças mais relevantes, por característica, foram entre os valores estimados e reais dos componentes genético aditivo e residual, os quais se mostraram sempre superestimados, tomando como base seus valores reais.

A variância de dominância contribuiu com aproximadamente $70 \%$ do seu valor real para a superestimação da variância aditiva e com outros 30\% para a do resíduo, sob baixa herdabilidade. Essa contribuição foi cerca de 51\% para a superestimação da variância aditiva e de $49 \%$ para a da variância residual, sob alta herdabilidade. A mesma relação mostrou-se imprecisa para a característica de média herdabilidade. Nesse sentido, houve redistribuição da variância de dominância entre os componentes aditivo e residual, proporcionando valores superestimados desses componentes, já que o modelo de análise ignorou os efeitos da dominância.

Especialmente com relação aos valores reais, a razão entre as variâncias de dominância e fenotípica foi de 10, 18 e 33\% sob baixa, média e alta herdabilidades, respectivamente, representando o percentual com que os efeitos da dominância influenciaram a expressão dessas características. Para a razão entre as variâncias de dominância e genotípica, verificaram-se os valores de 42 , 46 e $47 \%$ nas herdabilidades baixa, média e alta, nesta ordem. Nesse ponto, vale enfatizar que foi detectada covariância entre os efeitos genéticos aditivos e de dominância na população, o que indica que esses efeitos estavam correlacionados, ainda que de forma inexpressiva, pois se tratava de populações não-selecionadas, nas quais esperava-se que as frequências alélicas se afastassem pouco do seu valor inicial de 0,50 e que a endogamia não se elevasse consideravelmente ao longo das gerações. Ressalta-se que os coeficientes da endogamia média real e estimada

Tabela 1 - Valores reais e estimados dos parâmetros genéticos do modelo com apenas efeitos aditivos dos genes para características de baixa, média e alta herdabilidades

\begin{tabular}{|c|c|c|c|c|c|c|}
\hline \multirow{3}{*}{$\begin{array}{l}\text { Parâmetro } \\
\text { genético }^{1}\end{array}$} & \multicolumn{6}{|c|}{ Modelo aditivo } \\
\hline & \multicolumn{2}{|c|}{ Baixa herdabilidade $\left(\mathrm{h}^{2}=0,15\right)$} & \multicolumn{2}{|c|}{ Média herdabilidade $\left(\mathrm{h}^{2}=0,30\right)$} & \multicolumn{2}{|c|}{ Alta herdabilidade $\left(\mathrm{h}^{2}=0,60\right)$} \\
\hline & Valor real & Valor estimado & Valor real & Valor estimado & Valor real & Valor estimado \\
\hline$\sigma_{P}^{2 \mathrm{a}}$ & 6,149 & 6,127 & 2,854 & 2,939 & 1,406 & 1,412 \\
\hline$\sigma_{G}^{2 b}$ & 1,014 & - & 0,812 & - & 0,825 & - \\
\hline$\sigma_{A}^{2 c}$ & 1,014 & 1,043 & 0,812 & 0,894 & 0,825 & 0,806 \\
\hline$\sigma_{D}^{2 d}$ & 0,0 & - & 0,0 & - & 0,0 & - \\
\hline$\sigma_{E}^{2} \mathrm{e}$ & 5,170 & 5,085 & 2,055 & 2,045 & 0,589 & 0,606 \\
\hline $\mathrm{h}_{a}^{2 \mathrm{f}}$ & 0,16 & 0,17 & 0,28 & 0,30 & 0,59 & 0,57 \\
\hline
\end{tabular}

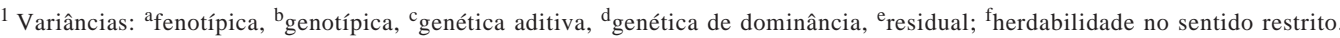


Tabela 2 - Valores reais e estimados dos parâmetros genéticos do modelo com efeitos aditivos e de dominância para características de baixa, média e alta herdabilidades

\begin{tabular}{|c|c|c|c|c|c|c|}
\hline \multirow{3}{*}{$\begin{array}{l}\text { Parâmetro } \\
\text { genético }^{1}\end{array}$} & \multicolumn{6}{|c|}{ Modelo heterórico } \\
\hline & \multicolumn{2}{|c|}{ Baixa herdabilidade $\left(h^{2}=0,15\right)$} & \multicolumn{2}{|c|}{ Média herdabilidade $\left(h^{2}=0,30\right)$} & \multicolumn{2}{|c|}{ Alta herdabilidade $\left(\mathrm{h}^{2}=0,60\right)$} \\
\hline & Valor real & Valor estimado & Valor real & Valor estimado & Valor real & Valor estimado \\
\hline$\sigma_{P}^{2 \mathrm{a}}$ & 6,630 & 6,707 & 3,580 & 3,792 & 1,964 & 2,037 \\
\hline$\sigma_{G}^{2 b}$ & 1,604 & - & 1,451 & - & 1,377 & - \\
\hline$\sigma_{E}^{2 e}$ & 5,091 & 5,274 & 2,105 & 2,351 & 0,575 & 0,897 \\
\hline $\mathrm{h}_{a}^{2 \mathrm{f}}$ & 0,14 & 0,21 & 0,24 & 0,38 & 0,41 & 0,56 \\
\hline
\end{tabular}

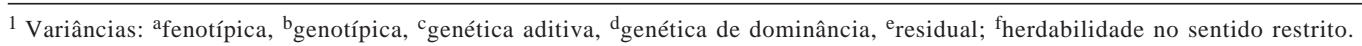

ficaram em torno de 2,5 e 3,5\%, respectivamente, para todas as populações.

A variância de dominância real correspondeu a 70, 78 e $79 \%$ da variância genética aditiva sob baixa, média e alta herdabilidades, respectivamente (Tabela 2). Esses percentuais elevados podem ter sido decorrentes de frequências alélicas mais próximas da frequência inicial intermediária, que maximiza a variância de dominância, uma vez que as populações não foram selecionadas, e também em razão do número considerável de locos controlando a expressão fenotípica da característica. Já o fato de a variância de dominância ter sido inferior à variância aditiva faz sentido, mesmo em um genoma com $100 \%$ dos locos com dominância completa, pois a variância desse efeito depende das frequências gênicas e do desvio da dominância, enquanto a variância aditiva depende dos efeitos aditivos, das frequências gênicas e, ainda, do desvio da dominância. Logo, teoricamente, o próprio desvio da dominância também contribui para a variância aditiva, o que significa que a variância genética aditiva não implica necessariamente apenas ação gênica aditiva.

As herdabilidades reais de 0,24 e 0,41 foram menores que os valores ajustados inicialmente de 0,30 e 0,60, mas não mudaram a classificação das características como de média e alta herdabilidades, nesta ordem. Paralelamente à fixação do valor inicial da variância genética aditiva em 0,90, a variância residual acabou, do mesmo modo, conservada entre os modelos. Assim, considerando que a variância aditiva real apresentou valor em torno de 0,90, independentemente do modelo; que a inclusão da dominância acarretou surgimento da variância deste efeito e de sua covariância com os efeitos aditivos, aumentando a variância genotípica; e que a variância residual manteve-se praticamente inalterada em relação aos seus valores no modelo aditivo, então o aumento da variância fenotípica sob o modelo heterótico decorreu sobretudo dos efeitos da dominância e, dessa forma, as herdabilidades reais ficaram reduzidas.

Quanto ao viés (Tabela 3), determinado em percentual, para as estimativas dos parâmetros genéticos, os valores foram de magnitude mais relevante sob o modelo heterótico, para o qual a variância genética aditiva foi superestimada em 49, 69 e 41\% sob baixa, média e alta herdabilidades, respectivamente. Nessa mesma sequência, a variância residual foi superestimada em 4, 12 e 56\%. Dos componentes estimados, a variância fenotípica foi a que apresentou menor viés em cada característica avaliada.

Tabela 3 - Viés, em porcentagem, dos parâmetros genéticos obtidos nos modelos aditivo e heterótico, sob baixa, média e alta herdabilidades

\begin{tabular}{|c|c|c|c|c|c|c|}
\hline \multirow{2}{*}{$\begin{array}{l}\text { Parâmetro } \\
\text { genético }^{1}\end{array}$} & \multicolumn{3}{|c|}{ Modelo aditivo } & \multicolumn{3}{|c|}{ Modelo heterótico } \\
\hline & $h^{2}=0,15$ & $\mathrm{~h}^{2}=0,30$ & $\mathrm{~h}^{2}=0,60$ & $h^{2}=0,15$ & $\mathrm{~h}^{2}=0,30$ & $\mathrm{~h}^{2}=0,60$ \\
\hline$\sigma_{P}^{2 \mathrm{a}}$ & $-0,36$ & $+2,98$ & $+0,43$ & $+1,16$ & $+5,92$ & $+3,72$ \\
\hline$\sigma_{A}^{2 c} \mathrm{c}$ & $+2,86$ & $+10,10$ & $-2,30$ & $+49,43$ & $+69,13$ & $+40,62$ \\
\hline$\sigma_{D}^{2 \mathrm{~d}}$ & - & - & - & - & - & - \\
\hline
\end{tabular}

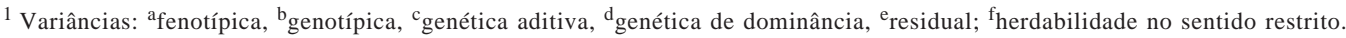


Os valores superestimados das variâncias genética aditiva e residual, como já mencionado, podem ser atribuídos à escolha do modelo para avaliação genética, no qual os desvios da dominância foram totalmente ignorados, situação que provavelmente acontece nas avaliações genéticas quando se desconsidera a dominância. Assim, o valor que se esperaria ser estimado para o componente da variância de dominância, caso esse efeito genético tivesse sido incluído no modelo de análise, foi redistribuído entre os componentes aditivo e residual estimados.

O fato de as superestimativas terem sido importantes pode ser atribuído à própria magnitude do efeito da dominância, função do tipo de dominância, que, neste estudo, foi completa, e do número de locos contendo desvios, no caso, todos; e ainda ao modo como a população foi estruturada, em famílias de irmãos completos.

Superestimações expressivas da variância genética aditiva também foram obtidas por Norris et al. (2002) ao avaliarem, por meio do modelo de reprodutor com inclusão apenas dos efeitos genéticos aditivos, populações simuladas diferentes quanto às variâncias aditiva e de dominância e quanto ao número de famílias de irmãos completos. Segundo os autores, as superestimativas do componente aditivo aumentaram com o número das famílias de irmãos completos e com a magnitude dos efeitos da dominância.

A superestimação do componente aditivo foi numericamente importante para as três características, enquanto a do componente residual foi mais intensa na característica de alta herdabilidade (Tabela 3). Como consequência, observou-se viés mais elevado nas estimativas de herdabilidade restrita para as características de baixa e média herdabilidades, isto é, da ordem de 50 e 58\%, respectivamente, em comparação ao viés de $37 \%$ sob alta herdabilidade, o que pode comprometer mais seriamente o ganho genético para aquelas características caso o modelo de avaliação não considere os efeitos da dominância.

Diferentemente, Tempelman \& Burnside (1991) encontraram estimativas de herdabilidade bem menos viesadas ao analisarem registros de primeira lactação de vacas da raça Holandesa empregando o modelo animal. Esses autores registraram aumentos médios de 2,5 e 4,4\% nas respectivas herdabilidades da produção de leite e de gordura quando os efeitos genéticos foram assumidos como totalmente aditivos em comparação aos valores obtidos quando os efeitos de dominância foram incluídos na análise.
De modo geral, ambas as correlações de Pearson e Spearman (Tabela 4) apresentaram valores de moderados a altos e foram bastante semelhantes entre si para determinado modelo genético ou característica. Esses valores aumentaram de acordo com a herdabilidade, em decorrência da redução da influência dos fatores ambientais.

Para o modelo com ação gênica de dominância, foram analisados dois critérios de comparação: 1) correlação entre valor genético verdadeiro e predito (fora dos parênteses); e 2) correlação entre valor genotípico verdadeiro e genético predito (entre parênteses). Sob esse modelo, pelo primeiro critério, as correlações obtidas foram de menor magnitude, uma vez que os valores genéticos preditos estavam contaminados pelos desvios da dominância, que não puderam ser separados na análise empregando-se o modelo misto aditivo. Conforme verificado (Tabela 2), as variâncias aditivas estimadas foram mais similares às variâncias genotípicas reais. Também o fato de a herdabilidade real ter sido inferior a 0,30 ou a 0,60 contribuiu para reduzir o valor dessa correlação.

Correlações mais altas (Tabela 4) foram estimadas adotando-se o segundo critério, pois o valor genotípico verdadeiro incluía ambos os efeitos aditivos e de dominância, da mesma forma como os valores genéticos preditos. Nesse caso, as correlações foram bastante semelhantes àquelas obtidas sob o modelo genético aditivo, quando foram correlacionados os valores genéticos aditivos verdadeiros com os preditos na ausência de dominância, situação em que as variâncias aditivas reais e estimadas foram similares (Tabela 1 ).

Com dados de campo, Culbertson et al. (1998) e Varona et al. (1998) obtiveram correlações superiores a 0,99 entre valores genéticos preditos por meio de modelos mistos que incluíam ou não o efeito da dominância no estudo de características em suínos e da estatura em gado

Tabela 4 - Correlações de Pearson e Spearman entre os valores genéticos verdadeiros e preditos, nos modelos propostos, considerando os animais avaliados, nas três herdabilidades $\left(\mathrm{h}^{2}\right)$

\begin{tabular}{|c|c|c|c|}
\hline \multirow[t]{2}{*}{ Correlação } & \multicolumn{3}{|c|}{ Valor de herdabilidade $\left(\mathrm{h}^{2}\right)$} \\
\hline & $\mathrm{h}^{2}=0,15$ & $\mathrm{~h}^{2}=0,30$ & $\mathrm{~h}^{2}=0,60$ \\
\hline & \multicolumn{3}{|c|}{ Modelo aditivo } \\
\hline Pearson & 0,68 & 0,70 & 0,83 \\
\hline Spearman & 0,66 & 0,69 & 0,82 \\
\hline \multicolumn{4}{|c|}{ Modelo heterótico } \\
\hline Pearson & $0,62(0,67) a$ & $0,61(0,72)$ & $0,68(0,84)$ \\
\hline Spearman & $0,60(0,64)$ & $0,59(0,70)$ & $0,67(0,83)$ \\
\hline
\end{tabular}

a Números entre parênteses referem-se a correlações entre valores genotípicos verdadeiros e genéticos preditos. 
de leite, respectivamente. Segundo Culbertson et al. (1998), a inclusão no modelo de ambos os efeitos da dominância e da endogamia tem pouca influência sobre a predição do mérito genético aditivo, enquanto, para Varona et al.(1998), as mudanças desprezíveis poderiam ter sido causadas pelo número pequeno de famílias de irmãos completos (cerca de 7\%), pelo tamanho pequeno da maioria dessas famílias e pelo nível baixo de endogamia na população avaliada. Segundo Varona et al. (1998), correlações mais baixas foram obtidas para animais com famílias estruturadas predominantemente com irmãos completos.

Apesar de as correlações encontradas terem tido magnitude menor que as citadas por esses autores, as mesmas foram estabelecidas entre os valores genéticos verdadeiros dos animais, conhecidos na simulação, e os seus valores genéticos preditos. De modo geral, quanto menos rigorosa a seleção, maior o percentual de indivíduos selecionados em comum pelos critérios adotados (Tabela 5).

No modelo aditivo, a seleção de $1 \%$ dos melhores animais acarretou em 32,2; 25,0 e 33,9\% de animais selecionados em comum pelos valores genéticos verdadeiros e preditos nas características de baixa, média e alta herdabilidades, respectivamente. Reduzindo a intensidade de seleção, houve maior coincidência de animais selecionados, ou seja, para 30\% dos melhores indivíduos, 61,5; 63,8 e 73,4\% dos animais foram idênticos por esse critério de classificação, em relação às herdabilidades baixa, média e alta, respectivamente.

Com ação gênica de dominância, o percentual de animais selecionados em comum pelo primeiro critério foi inferior ao daqueles selecionados pelo segundo em todas as situações, com exceção da característica de baixa herdabilidade na mais alta intensidade de seleção (28,3 vs 24,4\%). A diferença entre os critérios aumentou de acordo com a herdabilidade. Exemplificando, para 15\% de intensidade de seleção, o percentual de animais selecionados em comum pelo critério 1 versus critério 2 foi de 47,5 vs $49,1 \%$; 46,4 vs $52,9 \%$; e 50,2 vs $64,5 \%$ sob baixa, média e alta herdabilidade, nesta ordem. Pelo segundo critério, o percentual de indivíduos selecionados em comum, escolhidas uma herdabilidade e intensidade de seleção, foi mais próximo do percentual para o genoma com apenas efeitos aditivos dos genes, corroborando a similaridade de suas correlações.

Esses resultados indicam alterações na ordenação dos animais nos modelos genéticos aditivo e de dominância pelos critérios de classificação adotados. Essas alterações foram mais intensas quando o primeiro critério foi aplicado ao modelo com dominância nos locos, uma vez que os valores genéticos preditos a partir do modelo misto aditivo estavam contaminados pelos desvios da dominância.

Tabela 5 - Percentual (número) de animais que seriam selecionados em comum para 1; 5; 15 e 30\% dos mais bem classificados com base nos critérios 1 e 2, considerando os modelos genéticos propostos, nas três herdabilidades ( $\mathrm{h}^{2}$ )

\begin{tabular}{|c|c|c|c|c|}
\hline Modelo genético & $1 \%(180)$ & $5 \%(900)$ & $15 \%(2.700)$ & $30 \%(5.400)$ \\
\hline & \multicolumn{4}{|c|}{$\mathrm{h}^{2}=0,15$} \\
\hline Modelo aditivo & $32,22(58)$ & $40,22(362)$ & $50,44(1.362)$ & $61,50(3.321)$ \\
\hline Modelo heterótico pelo critério 1 & $28,33(51)$ & 34,78 (313) & $47,52(1.283)$ & $58,76(3.173)$ \\
\hline \multirow[t]{2}{*}{ Modelo heterótico pelo critério 2} & $24,44(44)$ & 36,56 (329) & $49,07 \quad(1.325)$ & $60,31 \quad(3.257)$ \\
\hline & \multicolumn{4}{|c|}{$\mathrm{h}^{2}=0,30$} \\
\hline Modelo aditivo & $25,00(45)$ & $39,56(356)$ & $52,37(1.414)$ & $63,76(3.443)$ \\
\hline Modelo heterótico pelo critério 1 & $22,22(40)$ & 33,89 (305) & $46,44(1.254)$ & $58,54(3.161)$ \\
\hline \multirow[t]{2}{*}{ Modelo heterótico pelo critério 2} & $26,67(48)$ & 39,78 (358) & $52,93(1.429)$ & $64,44(3.480)$ \\
\hline & \multicolumn{4}{|c|}{$\mathrm{h}^{2}=0,60$} \\
\hline Modelo aditivo & $33,89(61)$ & $51,78(466)$ & $63,33(1.710)$ & $73,37 \quad(3.962)$ \\
\hline Modelo heterótico pelo critério 1 & 23,89 (43) & $37,00(333)$ & $50,22(1.356)$ & $62,56(3.378)$ \\
\hline Modelo heterótico pelo critério 2 & $37,78(68)$ & $53,00(477)$ & $64,52(1.742)$ & $73,59(3.974)$ \\
\hline
\end{tabular}

Critério 1: correlação entre valores genéticos verdadeiros e preditos.

Critério 2: correlação entre valores genotípicos verdadeiros e genéticos preditos.

\section{Conclusões}

A análise de características quantitativas influenciadas por ação gênica de dominância quando se ignora esse efeito genético não-aditivo apresenta estimativas viesadas dos componentes de variância e herdabilidade. É necessária a incorporação desse efeito no modelo. A variância de dominância real, não-acomodada pelo modelo misto aditivo, é redistribuída entre os componentes genético aditivo e residual estimados, o que implica superestimação desses componentes. A não-inclusão do efeito de dominância reduz a acurácia da avaliação genética dos animais. 


\section{Literatura Citada}

BOLDMAN, K.G.; KRIESE, L.A.; Van VLECK, D.L. et al. A manual for use of MTDFREML. A set of programs to obtain estimates of variance and covariance [DRAFT] Lincoln: USDA/ARS, 1995. 120p.

CULBERTSON, M.S.; MABRY, J.W.; MISZTAL, I. et al. Estimation of dominance variance in purebred Yorkshire swine. Journal of Animal Science, v.76, p.448-451, 1998.

EUCLYDES, R.F. Uso do sistema para simulação Genesys na avaliação de métodos de seleção clássicos e associados a marcadores moleculares. 1996. 149f. Tese (Doutorado em Genética e Melhoramento) - Universidade Federal de Viçosa, Viçosa, MG, 1996.

FALCONER, D.S. Introdução à genética quantitativa. Tradução de SILVA, M.A.; SILVA, J.C. Viçosa, MG: Imprensa Universitária, 1987. 279p.

HAYES, B.J.; MILLER, S.P. Mate selection strategies to exploit across-and-within-breed dominance variation. Journal of Animal Breeding and Genetics, v.117, p.347-359, 2000.

ISHIDA, T.; MUKAI, F. Estimation of dominance genetic variances for reproductive traits and growth traits of calves in Japanese Black cattle. Journal of Animal Science, v.75, p.285-294, 2004.
MISZTAL, I. Estimation of variance components with largescale dominance models. Journal of Dairy Science, v.80, p.965-974, 1997.

NORRIS, D.; MAO, L.L.; COETZEE, R.J. Effect of population structure and underlying magnitude of dominance genetic effects on the estimation of additive and dominance genetic variations. South African Journal of Animal Science, v.32, n.2, p.113-120, 2002.

SCHAEFFER, L.R. Computing simplifications for non-additive genetic models. Journal of Animal Breeding and Genetics, v.120, p.394-402, 2003.

STATISTICAL ANALYSIS SYSTEM - SAS. User's guide: statistics. Version 8.0, Cary: SAS Institute, 1999. v.1. 1243p.

TEMPELMAN, R.J.; BURNSIDE, E.B. Additive and dominance genetic variation for dairy production traits under an animal model. Journal of Animal Breeding and Genetics, v.108, p.330-342, 1991.

VanRADEN, P.M.; LAWLOR, T.J.; HOESCHELE, I. Use of reproductive technology to estimate variances and predict effects of gene interactions. Journal of Dairy Science, v.75, p.2892-2901, 1992.

VARONA, L.; MISZTAL, I.; BERTRAND, J.K. et al. Effect of full sibs on additive breeding values under the dominance model for stature in United States Holsteins. Journal of Dairy Science, v.81, p.1126-1135, 1998. 